\title{
https://doi.org/10.30853/filnauki.2018-5-2.5
}

\section{Би Цзюньжу}

ПРОБЛЕМА ВЫБОРА И ПУТИ ЕЕ РЕШЕНИЯ В ДВУЧАСТНЫХ РАССКАЗАХ А. И.

\section{СОЛЖЕНИЦЫНА}

В статье анализируется проблема выбора в двучастных рассказах А. И. Солженицына, написанных в 1993-1998 годах. Целью работы стало раскрыть причину появления проблемы нравственного выбора, который стоит перед человеком в разных компромиссных ситуациях. Авторская концепция личности была выражена в мужских и женских образах. По мнению писателя, человеку нельзя отказываться от борьбы за собственные принципы, потому что всего одна уступка способна привести к трагическому компромиссу. Вера в Бога и стойкость личности перед соблазнительным материальным благополучием могут сохранить душу человека, помочь ему остаться самим собой.

Адрес статьи: www.gramota.net/materials/2/2018/5-2/5.html

\section{Источник}

\section{Филологические науки. Вопросы теории и практики}

Тамбов: Грамота, 2018. № 5(83). Ч. 2. С. 241-245. ISSN 1997-2911.

Адрес журнала: www.gramota.net/editions/2.html

Содержание данного номера журнала: www.gramota.net/materials/2/2018/5-2/

\section{(c) Издательство "Грамота"}

Информация о возможности публикации статей в журнале размещена на Интернет сайте издательства: www.gramota.net

Вопросы, связанные с публикациями научных материалов, редакция просит направлять на адрес: phil@gramota.net 
6. Кошубаев Д. П. Был счастья день // Кошубаев Д. П. Абраг: роман, повесть. Нальчик: Эльбрус, 2004. С. 93-193.

7. Лотман Ю. М. Память в культурологическом освещении // Лотман Ю. М. Избранные статьи: в 3-х т. Таллин: Александра, 1992. Т. 1. С. 200-202.

8. Набоков В. В. Другие берега // Набоков В. В. Избранное. М.: Худож. лит., 1988. С. 10-370.

9. Ремизов В. А. Духовность как культурная ценность личности // Философские науки. 1997. № 2. С. 158-161.

10. Токарева С. Б. Духовность в горизонте повседневности и за его пределами // Личность. Культура. Общество. М., 2005. Вып. 4 (28). С. 281-292.

11. Узденова Ф. Т. Художественное пространство карачаево-балкарской поэзии: этнокультурный контекст. Нальчик: Принт Центр, 2016. 212 с.

12. Хакуашева М. А. Дорога домой // Дружба народов. 2006. № 8. С. 47-85.

13. Хакуашева М. А. Литературные архетипы в художественных произведениях адыгских писателей. Нальчик: Изд-во КБНЦ РАН, 2007. $378 \mathrm{c}$.

14. Чипчиков Б. М. Нерестились рыбы в свете лунном // Чипчиков Б. М. Мы жили рядышком с Граалем. М.: Эльбрусоид, 2007. C. 82-129.

\title{
INTERTEXT AS SPIRITUAL SPACE OF CULTURAL MEMORY
}

\author{
Bazieva Gul'fiya Dzhamalovna, Ph. D. in Philosophy \\ Institute for the Humanities Research - Branch of the Kabardino-Balkarian Scientific Centre \\ of the Russian Academy of Sciences, Nalchik \\ gbaz@mail.ru
}

Due to active globalization processes that form single information space intertext becomes spiritual space of cultural memory. Spiritual and moral issues in intertext are developed at several levels: mythological, religious, moral and ethical ones. Modern literature refers to folklore subjects and traditional values that act as a code of ethnic identification, the basis of a cultural matrix. The novelty of the study is determined by the culturological approach to the analysis of intertext as an important phenomenon representing both ethnic and universal human spiritual values.

Key words and phrases: spirituality; ethnic identity; intertext; national literature; cultural matrix; Kabardino-Balkaria.

УДК 821.161 .1

https://doi.org/10.30853/filnauki.2018-5-2.5

В статье анализируется проблема выбора в двучастных рассказах А. И. Солженицына, написанных в 1993-1998 годах. Целью работы стало раскрыть причину появления проблемы нравственного выбора, который стоит перед человеком в разных компромиссных ситуациях. Авторская концепция личности была выражена в мужских и женских образах. По мнению писателя, человеку нельзя отказываться от борьбы за собственные принципы, потому что всего одна уступка способна привести к трагическому компромиссу. Вера в Бога и стойкость личности перед соблазнительным материальным благополучием могут сохранить душу человека, помочь ему остаться самим собой.

Ключевые слова и фразы: Александр Солженицын; двучастные рассказы; тема выбора; ситуация компромисса; художественная концепция личности; потеря веры.

\section{Би Цзюньжу}

Московский государственный университет имени М. В. Ломоносова byr1017@mail.ru

\section{ПРОБЛЕМА ВЫБОРА И ПУТИ ЕЕ РЕШЕНИЯ В ДВУЧАСТНЫХ РАССКАЗАХ А. И. СОЛЖЕНИЦЫНА}

Как известно, А. И. Солженицын не только обращается к традиционным жанрам, но и создает новые: рассказы-миниатюры («Крохотки»), опыт художественного исследования («Архипелаг ГУЛАГ»), повествование в отмеренных сроках («Красное колесо») и другие. Среди новых жанровых образований, созданных писателем, особое место занимают двучастные рассказы. Они составляют целый цикл, за которым в современном литературоведении закрепилось название «рассказы 1990-х годов».

Новый цикл двучастных рассказов публикуется в «Новом мире» с 1995 года [2, с. 12]. По мнению американского слависта Р. Темпеста, двучастные рассказы представляют собой очередной пример жанрового эксперимента в творчестве писателя [8, с. 68]. Их сюжетной основой является сопоставление двух граней восприятия героями действительности и двух принципов построения человеком собственной жизни, когда каждый из героев оказывается в ситуации выбора. М. М. Голубков подчеркивает, что выбор каждого человека сказывается, по Солженицыну, не только на частной жизни человека, но и на судьбах нации, судьбах мира [2, с. 97]. Чаще всего в этих рассказах идет речь о выборе - между свободой и несвободой, жизнью и смертью, предательством и верностью. 
Рассказ «Эго» был написан в 1994 году, «На краях» - в 1994-1995 гг. Факт публикации «Эго» и «На краях» в пятом номере «Нового мира» в 1995 г. формирует композиционное единство двучастных рассказов. В. В. Гуськов в статье «Многообразие связей рассказа “Эго” с исторической эпопеей "Красное колесо”» определяет «Эго» как «первый двучастный рассказ» [4, с. 108]. По утверждению П. Е. Спиваковского, «Эго» и «На краях» представляют собой мини-цикл о феномене человеческого «я», о взаимоотношениях между историей и «я» [7, с. 68-69]. Исследователь подчеркивает, что оба рассказа тесно связаны друг с другом.

Р. Темпест полагает, что две части рассказов имеют не сюжетную, а тематическую связь, иногда «даже главный персонаж в них один и тот же» [8, с. 68]. По нашему мнению, эти рассказы изначально тяготеют к созданному Солженицыным жанру двучастных. Композиционный принцип, по которому они строятся, можно обозначить следующим образом: либо Солженицын сопоставляет два периода жизни одного человека, которые в художественном мире произведения резко противопоставлены, либо же героями двух частей рассказа могут быть два различных человека, нравственные позиции которых сопоставляются или противопоставляются. К числу двучастных рассказов можно отнести следующие произведения, написанные в 1993-1998 гг.: «Эго», «На краях», «Молодняк», «Настенька», «Абрикосовое варенье», «Всё равно», «На изломах», «Желябугские Выселки» [6].

Нельзя сказать, что двучастные рассказы глубоко и всесторонне исследованы современным литературоведением, хотя за последние десятилетия появился ряд работ, анализирующих те или иные аспекты их проблематики и их художественные особенности, среди которых «Проза А. Солженицына 1990-х годов. Художественный мир. Поэтика. Культурный контекст» под редакцией А. В. Урманова [4], «Феномен А. И. Солженицына: новый взгляд (к 80-летнию со дня рождения)» П. Е. Спиваковского [7] и др.

К двучастным рассказам обращается и М. М. Голубков в главе «Соблазн и трагедия компромисса» в книге об А. И. Солженицыне из серии «Перечитывая классику» [2]. Однако художественная природа рассказов, концепция личности, заявленная в них, и авторская позиция писателя, так же, как и формы ее выражения, требуют особого изучения.

Основной вопрос, который поднимает в двучастных рассказах А. И. Солженицын, связан с природой компромисса, с его истоками, с тем, почему так незаметно человек склоняется к некой сделке с совестью или с обстоятельствами, предавая своих близких или самого себя. С точки зрения писателя, компромисс, следствием которого непременно становится предательство, обусловлен тупиком гуманистического сознания. Причем А. И. Солженицын утверждает важность нравственной стойкости, которая должна проявляться индивидуумом перед внешними обстоятельствами, пытающимися его подчинить и сломить.

Вопрос о том, какой выбор должен делать человек перед соблазном компромисса, поднимается автором и в других его произведениях: например, в романе «В круге первом» нравственный выбор трактуется как «проявление внутренней свободы» [Там же, с. 96]; в произведениях 1960-х гг. появляется тема ценностного «самостоянья» героя в ситуации насилия, верности собственным ценностям, способность следовать собственным нравственным ориентирам [10], однако в двучастных рассказах тема выбора вынесена на передний план, в них она стала основной.

Главный герой «Эго» - сельский интеллигент Павел Васильевич Эктов, который в годы Гражданской войны стал убежденным сторонником крестьянского повстанческого движения и сражался под руководством знаменитого атамана Антонова. Сам герой «всем своим воспитанием и гуманистической традицией был всегда всей душой против всякого кровопролития» [6, с. 276]. Для него неприемлемо было «жестокое междоусобное уничтожение соотечественников... под железной подошвой большевицкой диктатуры» [Там же, с. 272]. Сочувствие к страданиям народа приводит героя к участию в Антоновском восстании.

Однако сам герой смог предчувствовать возможные опасности, к которым привело его решение об участии в крестьянской армии, поэтому он в «нарождающемся штабе Антонова» быстро выбрал для себя псевдоним «Эго». П. Е. Спиваковский отмечает, что случайный выбор вымышленной фамилии имеет предопределенное значение, так как причина предательства проявляется в «эгоистическом счете» [7, с. 70]. По мнению ученого, «служение своему человеческому “эго”» представляет собой важнейшую цель Эктова в жизни.

Очевидно, что Павел Васильевич любил свою семью. Жена и дочь - это его высшее счастье. Герой сильно волновался за родных перед самым отъездом из Тамбова в армию восставших. Страдания разлуки выражены вопросами из внутреннего монолога Эктова: «...как оставить вас? И - на какие испытания? на какие опасности? даже просто на голод?» [6, с. 276]. Активный участник Антоновского восстания, командир Антоновского штаба, он ни на минуту не забывает о семье, при первой же возможности посылает жене устную весточку о себе с «верной бабой с махоткой молока» [Там же, с. 282].

В конце первой части рассказа герой был «выдан чекистам по доносу соседской бабы» [Там же, с. 286]. Арест разделяет его жизнь на две части, причем в первой части он играет роль важного члена Антоновского восстания, а во второй - пленника-предателя. Когда Эктов сидел в лубянской тюрьме, самая важная задача, по его мнению, состояла в том, чтобы сохранить свою реальную биографию в тайне, таким образом он мог обеспечить безопасность родных, а он сам «давно обвыкся с мыслью о смерти» [Там же, с. 287]. Ведь семья представляет собой «извечную радость человека и извечную его уязвимость» [Там же, с. 281], а слабость героя родные люди, которые в итоге оказываются в заложниках.

Первым двум следователям не удалось ослабить «жизненную силу сопротивления» [Там же, с. 288] Эктова. Желание сохранить родных от опасного положения стало психологической опорой героя до того момента, когда третий следователь назвал его настоящее имя и имя жены, но он все еще надеялся, что жена с дочерью «поостереглась? сменила место? куда-нибудь уже переехала?..» [Там же, с. 289]. Тем не менее 
жизнь приготовила для Эктова страшное испытание: его семья, жена и дочь, стали заложниками большевиков, когда он попал в плен. В обмен на жизнь жены и дочери Эктов выбрал предательство своих товарищей по борьбе. Однако кровавая расправа, учиненная котовцами над повстанцами, дала герою понять, что ему и его семье тоже уготована страшная участь.

По мнению П. Е. Спиваковского, в рассказе «Эго» причиной предательства является «служение себе, своему человеческому стремлению к счастью» [7, с. 70]. Писатель сам в этом произведении отмечает, что без испытаний и потерь не может быть выбора, и если человек проявляет слабость и уступает, он не только теряет свои нравственные ориентиры, но и при этом ничего для себя не приобретает. Рассказ ставит весьма сложные нравственно-этические проблемы, возможно, не поддающиеся однозначному решению, но позиция писателя несомненна: он уверен, что главный герой совершил неправильный выбор, хотя этот выбор и может показаться читателю самым верным: «Пожертвовать женой и Маринкой, переступить через них - разве он мог??» [6, с. 290]. Выбрав свою семью и себя (недаром в рядах повстанцев у Эктова прозвище Эго), он одновременно потерял себя. Зрелище чудовищного расстрела котовцами повстанцев приводит Эго к полной жизненной катастрофе.

В рассказе «На краях» героем является знаменитый советский маршал Г. К. Жуков. Биография и деятельность «маршала победы» в российской исторической литературе традиционно осмысляются как героические. Однако А. И. Солженицын предлагает здесь иной взгляд.

Писатель подробно рассказывает о враждующих сторонах Антоновского восстания в рассказах «Эго» и «На краях». Эктов - участник восстания, а Жуков - младший командир Красной армии, воюющий под командованием Тухачевского.

В первой части «На краях» снова поднимается тема крестьянского повстанческого движения. Писатель показывает, как именно в борьбе с собственным народом, в жестоком уничтожении крестьян крепнет полководческий талант Жукова, будущего маршала победы. Встреча с Тухачевским во время тамбовской карательной операции представляет собой важнейший эпизод первой части рассказа, являющийся поворотным в становлении Жукова как военного человека и как командира. Будущий маршал не может свести глаз с командарма. Облик, поведение и речь Тухачевского вызывают у тогдашнего Ёрки Жукова лишь восхищение. По утверждению Р. Темпеста, «именно после встречи с Тухачевским в Жукове зарождается жажда славы, внеидеологическое стремление побеждать и блистать» [8, с. 71]. Подчиняясь командиру, молодой Жуков принимает участие «в уничтожении породившего его мира русской деревни» [2, с. 107]. Р. Темпест отмечает, что в рассказе «Жуков представлен как личность неавтономная, несуверенная, но честолюбивая и в определенной степени но лишь в определенной - одаренная» [8, с. 68]. Очевидно, что в характере Жукова А. И. Солженицын не видит твердости, напротив, соглашательство выступает тем качеством, которое помогает полководцу достичь карьерных высот, не быть репрессированным, оставаться у власти. Соглашательство помогает принять необходимость жестоких мер по отношению к восставшим крестьянам: «Пробандиченные деревни и вовсе сжигали, нацело. Оставались остовы русских печей да пепел» [6, с. 301]. Герой, «сын крестьянский» [Там же, с. 297], ведет себя без милосердия на родной земле. Можно сказать, что он предал тех, кого должен был ценить в жизни, участвуя в уничтожении крестьянства во время подавления Антоновского восстания. Первая часть рассказа, повествующая о молодости Жукова, заканчивается словами, комментирующими беспрецедентную жестокость красных: «Слишком крепко? А без того - больших полководцев не бывает» [Там же, с. 306]. Во второй части Жуков предстает уже пожилым человеком, пишущим мемуары. А. И. Солженицын кратко перечисляет основные факты биографии, излагаемые маршалом, и перед читателем проходят несколько десятилетий истории страны. Постаревший Жуков оправдывает жестокость, которой научился в период военных действий: «Полководец не может расслабить себя сожалением» [Там же, с. 314]. Однако основным качеством его личности и здесь выступает соглашательство, умение не перечить мнению начальства: он оправдывает Сталина, поддерживает его жестокую политику. Великий полководец за свою трудную и долгую жизнь привык к компромиссам, и вот ему совсем не трудно вставить в мемуары «две-три фразы» [Там же, с. 333] о стойком политруке Брежневе и внести другие вроде бы незначительные правки, чтобы книга была издана.

Писатель показывает в данном рассказе, как определенная историческая обстановка воздействует на формирование характера честного, как ему самому кажется, человека. Беда героя состоит не в его сломленной судьбе, а в «очередном компромиссе, на который он пошел» [2, с. 106].

В 1978 г. А. И. Солженицын в Гарвардской речи отмечал, что концепция «у человека нет задач выше земного счастья», в основе которой видны «представления о человеке как о центре существующего» и «гуманистическая автономность - провозглашенная и проводимая автономность человека от всякой высшей над ним силы» [5, с. 324], вела к тому, что «оставлены были сквозняки для зла, которые сегодня и продувают свободно» [Там же]. М. М. Голубков утверждает, что в интерпретации Солженицына «драма человека XX века состоит в слабости и искаженности его миросозерцания антропоцентрическими идеями Ренессанса и Просвещения» [2, с. 107].

Писатель изображает в «Эго» и «На краях» то, как судьбы субъективно честных людей были сломаны исторической обстановкой советского времени.

В первой части рассказа «Молодняк» говорится о встрече студента Алексея Коноплева в 1926 г. с профессором Воздвиженским, во второй - о встрече того же профессора в 1931 г. с работником ГПУ Коноплевым. А. И. Солженицын показывает, как кардинально меняется ситуация: в первой части от Воздвиженского зависит учеба будущего чекиста, во второй - от чекиста - жизнь профессора. На экзамене по сопромату в 1926 г. Коноплёв не готов отвечать, он простодушный и малограмотный бывший лудильщик, которого «сковырнули» 
с производства и заставили учиться в вузе. Коноплев - яркий представитель новой молодежи - «молодняка», для которого партийные ценности важнее человеческих. Профессор жалеет его и ставит «уд» - оценку «удовлетворительно», позволяющую нерадивому студенту продолжить обучение. В 1931 г. профессор, арестованный ГПУ по ложному обвинению, с удивлением узнает в следователе бывшего студента. Коноплев проявляет к нему внешнее сочувствие, вроде бы хочет помочь, а на самом деле угрозами и шантажом вынуждает подписать согласие сотрудничать, писать доносы «об настроениях в инженерной среде» [6, с. 345]. Как и в рассказе «На краях», прозаик показывает, как, однажды пойдя на небольшой компромисс, человек теряет часть себя, меняется навсегда, перестает быть прежним. Ведь предложение следователя ОГПУ, от которого, по всей видимости, не сможет отказаться арестованный профессор, есть следствие компромисса Воздвиженского, когда он, нарушив долг учителя, закрыл глаза на нерадивого ученика.

М. М. Голубков справедливо подчеркивает, что писатель «часто застает героя в трагической и безвыходной ситуации, когда тот беспомощен перед обстоятельствами, с которыми столкнулся» [2, с. 99]. Почти каждый герой в созданном Солженицыным художественном мире находится в ситуации выбора, выход из которой может найти лишь сам герой. Авторская концепция личности нашла свое отражение не только в мужских, но и в женских образах, созданных А. И. Солженицыным.

Рассказ «Настенька» отличается от других двучастных рассказов тем, что в каждой его части представлена судьба отдельной героини. В рассказе обеих девушек зовут Настями. Имя Анастасия в большинстве доступных источников переводится как «воскрешенная», «воскрешающая», «возвращенная к жизни» или же как «возрождение», «воскресение». Значимость семантики имени подчеркивается одним из важнейших эпизодов рассказа: вступление в ряды пионерской организации воспитанников детского дома, когда, повязывая красный галстук, ребятам дают новое имя: «...поступающих в пионеры переименовывали из Мишек и Машек - в Кимов, Владленов, Марксин и Октябрин» [6, с. 348]. Новые пионеры не расстраиваются от потери традиционных русских имен и «от души радуются» получению «новых революционных имен» [9, с. 51]. В этом рассказе имя связывает два женских образа и показывает, сколь драматичны, при всей внешней несхожести, последствия нравственного компромисса. В рассказе перед героинями, помимо всего прочего, стоит особый выбор, который может возникнуть только перед женщинами: уступать ли настойчивым домогательствам мужчины?

Настенька, героиня первого рассказа, была воспитана дедом, священником отцом Филаретом, с пяти лет. В детстве она «с любовью ходила на церковные службы» [6, с. 346]. Когда в 20-е годы о. Филарет был сослан на Соловки, Настенька старается избавиться от социального клейма, рвет родственные узы, пытаясь освободиться от наследия «поповской внучки». Поцеловав иконку Христа, которую героиня взяла с собой «по завету» дедушки, она порвала иконку «мелко-мелко, чтобы по обрывкам было не понять» [Там же, с. 347-348]. В первой части рассказа героиня, забывшая Бога, постепенно оказалась в абсолютном беспомощном состоянии и сделала выбор в пользу материального.

Судьба Анастасии Дмитриевны, героини второй части рассказа, складывается, казалось бы, по-другому. Дочь университетского профессора, она любила русскую литературу с детства, и «герои русских книг все рядышком, милые ее друзья или противники» [Там же, с. 357]. Став учителем литературы в школе, Анастасия Дмитриевна свое эмоционально-личностное восприятие литературы меняет на классово обусловленное, а преподавание литературы ведет в соответствии с образовательной политикой 20-х годов. Героиня отвыкает от свободы выражать собственную идею в эпоху, когда человек хочет «позабыть свое имя и званье, - На номер, на литер, на кличку сменять!» [Там же, с. 371]. Обеим героиням не дано понять, что они потеряли себя, встав на путь гуманистической автономии от высшей и благой силы, сущей над человеком, утратив веру в Бога. М. М. Голубков считает, что, с точки зрения писателя, трагедия современного человека проявляется в таких аспектах, как забвение «постоянной религиозной ответственности», исчезновение сознания «ответственности человека перед Богом и обществом» и «окончательное освобождение от морального наследства христианских веков» [2, с. 108].

По мнению Солженицына, именно дух «дает личности силы выжить и силы жить» [Цит. по: Там же, с. 100]. Герои большинства рассказов предпочли компромисс и утратили духовную поддержку. Не случайно сильной героиней у А. И. Солженицына становится именно женщина. Женские образы (например, «чудо духовности» Вера Гангарт из повести «Раковый корпус») занимают особое место в его творчестве, в различных произведениях мы сталкиваемся с силой женского характера, способностью женщин любить, их умением оставаться самими собой.

Итак, тема нравственного противостояния и этического выбора поднимается А. И. Солженицыным не случайно. Те испытания, которые пришлись на долю писателя, убедили его, что духовность, нравственность - это те категории, которые в условиях политических и социальных катаклизмов подвергаются трансформации в первую очередь. Писатель считает, что человек должен быть готов к борьбе за свою индивидуальность, к отстаиванию своих ценностей даже в условиях потрясений и насилия. Двучастные рассказы, с одной стороны, характеризуют важнейшие и все еще не освещенные литературой события национальной истории (Антоновское восстание, формирование трудармий, единицей которой становится Федор Иванович, автор письма, составляющего первую часть рассказа «Абрикосовое варенье», и др.), с другой стороны, рассказывают об авторской критике гуманистического сознания, которому принадлежат герои данных произведений. Двучастные рассказы имеют ярко выраженный дидактический характер и адресованы подрастающему поколению, которому ещё неоднократно предстоит делать выбор в жизни. Писатель отчетливо демонстрирует, что выбрать свободу, правду и справедливость хотя и сложнее, нежели предпочесть предательство и соглашательство или пойти на губительный компромисс с совестью, но перспективнее. 
1. Аркатова А. Е. «Чудо духовности» Веры Гангарт (о поэтике одного женского персонажа в повести А. Солженицына «Раковый корпус») // Вестник Рязанского государственного университета им. С. А. Есенина. 2013. № 3 (40). С. 89-96.

2. Голубков М. М. Александр Солженицын: в помощь преподавателям, старшеклассникам и абитуриентам. Изд-е 2-е. М.: Изд-во МГУ, 2001. $112 \mathrm{c.}$

3. Достоевский Ф. М. Полное собрание сочинений: в 30-ти т. Л.: Наука, 1972. Т. 28. Кн. 1. 552 с.

4. Проза А. Солженицына 1990-х годов. Художественный мир. Поэтика. Культурный контекст: международный сборник научных трудов / отв. ред. А. В. Урманов. Благовещенск: Изд-во БГПУ, 2008. 213 с.

5. Солженицын А. И. Публицистика: в 3-х т. Ярославль: Верхне-Волжское кн. изд-во, 1995. Т. 1. 720 с.

6. Солженицын А. И. Собрание сочинений: в 30-ти т. М.: Время, 2006. Т. 1. Рассказы и крохотки. 672 с.

7. Спиваковский П. Е. Феномен А. И. Солженицына: новый взгляд (к 80 -летию со дня рождения). М.: ИНИОН РАН, 1998. $135 \mathrm{c}$.

8. Темпест Р. Военный палимпсест: личность маршала Жукова в интерпретации Александра Солженицына // Вестник Рязанского государственного университета им. С. А. Есенина. 2013. № 3 (40). С. 67-76.

9. Урманов А. В. Художественное мироздание Александра Солженицына. М.: Русский путь, 2014. 624 с.

10. Чуриков Г. А. Герой как объект насильственного воздействия и как субъект ценностного «самостоянья» в творчестве А. И. Солженицына 1960-х годов: дисс. ... к. филол. н. Воронеж, 2007. 200 с.

\title{
PROBLEM OF CHOICE AND WAYS OF ITS SOLUTION IN TWO-PART STORIES BY A. I. SOLZHENITSYN
}

\author{
Bi Junru \\ Lomonosov Moscow State University \\ byr1017@mail.ru
}

The article analyzes the problem of choice in A. I. Solzhenitsyn's two-part stories written in 1993-1998. The work is aimed to reveal the cause for the appearance of the problem of moral choice, which faces the person in different compromise situations. The author's conception of personality was expressed in male and female images. According to the writer, a person should not abandon the struggle for his/her principles, because just one concession can lead to the tragic compromise. Faith in God and the personality's steadfastness in front of seductive material well-being can save the soul, help the individual to remain himself/herself.

Key words and phrases: Aleksandr Solzhenitsyn; two-part stories; theme of choice; compromise situation; literary conception of personality; loss of faith.

В статье рассматривается вопрос, малоизученный в кабардинском литературоведении: детская поэзия на примере творчества авторов раннего, промежуточного и современного периодов; прослеживается динамика развития и становления поэтики, жанровых особенностей литературы для детей, которую можно рассматривать как основное определяющее направление в контексте литературного процесса. В работе делается вывод о том, что детская литература представляет собой подсистему литературы, характеризуюшуюся особыми формально-содержательными и функциональньми признаками. Здесь также продемонстрированы соотнесенность современного этапа развития кабардинской детской поэзии с идейныли доминантами предьдущих периодов, перестановка тематических акиентов поэзии для детей.

Ключевые слова и фразы: детская литература; кабардинская литература; воспитание; поэзия; познание; фольклор; поэтика.

Бозиева Наима Борисовна, к. филол. н.

Кабардино-Балкарский государственный университет имени Х. М. Бербекова, г. Нальчик naimabozieva@mail.ru

\section{ДИНАМИКА РАЗВИТИЯ КАБАРДИНСКОЙ ДЕТСКОЙ ПОЭЗИИ}

«Детская литература обогащает представление юных читателей о прошлом и настоящем своего народа, помогает усваивать нравственные принципы, раскрывает красоту подвига человека во имя Родины» [1, с. 120]. Изучение ее диктуется, с одной стороны, требованиями глубокого научного освещения современного литературного процесса, с другой - задачами дальнейшего развития национальной, в частности кабардинской литературы.

Детская литература, по словам И. П. Мотяшова, обогащает нравственно, ибо «способствует самопознанию и самосовершенствованию личности, помогает понять свое предназначение, ориентироваться в мире» [4, с. 14].

Детская литература как явление кабардино-черкесского письменного творчества на несколько десятилетий моложе национальной литературы для взрослых. Однако, возникнув почти одновременно с последней, 